\title{
Filmar Malvinas: Apuntes sobre la guerra de Malvinas en el cine argentino contemporáneo
}

\author{
Ezequiel Fernández \\ Universidad del Cine, Buenos Aires \\ fernandezeze21@gmail.com
}

Recibido: 20 - agosto - 2018 / Aceptado: 24 - septiembre - 2018

\section{Resumen}

El presente artículo tiene como objetivo analizar y pensar las recurrencias sobre el género bélico en la representación de la Guerra de Malvinas en el cine argentino contemporáneo. Se propone como objeto de estudio los largometrajes Soldado argentino solo conocido por Dios, Malvineitor y Teatro de guerra a partir de los fundamentos teóricos y las herramientas de análisis, tanto cinematográficas como literarias, propuestas en Esto es la guerra, pibe: El cine bélico en la representación de la Guerra de Malvinas. Partiendo de la hipótesis que el género bélico posee resistencias de diversas índoles para afianzarse a la narrativa cinematográfica, se buscarán los puntos comunes y las diferencias con la filmografía precedente a 2018 para categorizar y comprender el estado del cine argentino en el presente.

Palabras clave: Guerra de Malvinas, cine argentino, cine bélico, literatura.

\section{Abstract}

This article aims to analyze and think about the recurrence of war genre on the representation of Malvinas/ Falklands war in the contemporary Argentinean cinema. The feature films Soldado argentino solo conocido por Dios, Malvineitor and Teatro de guerra are proposed as objects of study, both in a cinematographic and literary way, based on the theoretical basis and 
analytic tools suggested in Esto es la guerra, pibe: El cine bélico en la representación de la Guerra de Malvinas. Based on the hypothesis that the war genre presents all sorts of resistance to taking roots in cinematographic narration, we will look for similarities and differences with films prior to 2018 so as to categorize and understand the state of the current argentinean cinema.

Keywords: Malvinas/ Falklands war; argentinean cinema; war film; literature 
Hubieran sido amigos, pero se vieron una sola vez cara a cara, en unas islas demasiado famosas, y cada uno de los dos fue Cain, y cada uno, Abel. Juan López y John Ward, Jorge Luis Borges.

$\mathrm{L}$ a relación entre el cine argentino y la Guerra de Malvinas ha sido intermitente y conflictiva a lo largo de más de 35 años. A diferencia de otras artes como la literatura o el teatro, el abordaje de la guerra entre Argentina y Gran Bretańa de 1982 ha dado como resultado un escaso grupo de ficciones y documentales. Filmar la Guerra de Malvinas en mi país supone cierto acto de valentía tanto artístico como financiero. Más aún, hacer ficción sobre un conflicto que tiene como principal escenario islas desoladas por el viento y el frío ubicadas al fondo del mapamundi.

La guerra me atrapó en tanto cineasta como cinéfilo llevándome a la escritura de Esto es la guerra, pibe: El cine bélico en la representación de la Guerra de Malvinas (2018). Allí busqué comprender y ordenar una filmografía desprolija y compleja. Mi principal inquietud venía a raíz de la ausencia de una película bélica nacional en los términos estrictos del género. Una película de guerra que cumpla con los tropos del cine bélico y que se corresponda con otras películas del mismo género. A mi entender, el cine argentino es deudor de una película que haga honor a la gesta de Malvinas, una película que se ocupe de la experiencia del combate y retrate visualmente las proezas realizadas por nuestros soldados cuando apenas tenían 18 o 19 años de edad.

Rápidamente, el cine de ficción nacional se hizo eco de la contienda estrenándose en 1984 Los chicos de la guerra de Bebe Kamín. Dicho film respondía a una necesidad de indagar el panorama social anterior y posterior a la guerra, siendo insustancial en el desarrollo del relato bélico. Kamín realiza un recorrido por el estado de las instituciones fundamentales de una nación (el ejército, la escuela, la familia) afectadas por la Dictadura Cívico-Militar de 1976. Estas problemáticas también se observan en la película más recordada sobre el tema: Iluminados por el fuego (2005, Tristán Bauer). Con mayor presupuesto y recursos tecnológicos, esta película tampoco propuso un relato bélico genuino, imposibilitada por presuposiciones ideológicas y haciendo foco en la denuncia de crímenes cometidos por los superiores argentinos.

El cine bélico es un género de vasta trayectoria en la historia del cine. Hollywood ha sido la industria que ha puesto al género en el mapa y en las salas de todo el mundo tras el involucramiento de EE.UU. en la Primera y la Segunda Guerra Mundial. Es un género que ha sido adoptado por directores y guionistas de primera línea en todos los períodos de los últimos 70 años. En Esto es la guerra, pibe me propuse pensar esas condiciones que constituyen al género como tal, que hacen que la película de guerra no sea un western o un musical. Para ello fue necesario establecer ciertas reglas ineludibles, postulados que enmarcarán los elementos que componen a la película bélica. 
Siendo un género mayoritariamente masculino, de cuerpos entrenados y formados para el combate, se despliega en una gran diversidad de escenarios y topografías donde el héroe y su grupo deberán sobrevivir a los embates constantes del enemigo y las circunstancias propias de la guerra (el clima, el hambre, el desarraigo). En este contexto poco prometedor, emerge un valor que enlaza para la posteridad los vínculos homosociales del grupo: la camaradería. Si bien el cine bélico es célebre por su amplio abanico de héroes, en él cobran gran importancia el trabajo en equipo y la coordinación entre los compañeros. En las horas más oscuras será la calidez de la camaradería la que contendrá a aquellas almas desesperadas y ayudará a continuar avanzando en los infiernos del campo de batalla.

La condición de héroe no siempre se adjudica al protagonista apenas inicia el film. Ser un héroe es un camino de descubrimiento y aprendizaje, un crecimiento paulatino que se va dando a lo largo de la película hasta realizar lo que yo llamo "el acto heroico", ese hecho fundamental de una entrega espiritual y física superior a la de los demás hombres. En ese viaje asistimos a la transformación del individuo. Un soldado ingresa en la película de una manera y sale de ella transformado, elevado al haber realizado proezas inesperadas, inimaginables. Narrar la guerra implica considerar que en ese lapso de tiempo, donde se ven a flor de piel los horrores más impunes del ser humano, es posible la transformación. Es posible observar la metamorfosis de un individuo que pone a prueba su potencial. Guillermo Altares resume esta condición ineludible del género en su texto Esto es un infierno: Los personajes del cine bélico.

El cine bélico, el mejor cine bélico, habla de eso: de seres humanos prodigiosos y miserables, que en los momentos siempre difíciles de una guerra, pueden convertirse en lobos o en corderos, en bestias o en víctimas, aunque estos últimos siempre ocupan las listas más abultadas. Son seres que, aunque hayan podido sobrevivir a un conflicto, han dejado atrás una parte fundamental de sus existencias (Altares, 1999, pág. 283).

El cine argentino se manifestó ajeno a estas inquietudes para pensar la Guerra de Malvinas. La condición heroica ha sido siempre esquiva y las películas descreen del valor ineludible de la guerra como instancia de transformación. Para nuestro cine no hay aprendizaje posible en las Islas, no hay posibilidad de elevación personal. La guerra es retratada como una pesadilla recurrente, un recuerdo tortuoso en el que los protagonistas buscan la respuesta que justifique sus existencias.

En Esto es la guerra, pibe traté de comprender los impedimentos que hicieron que el cine nacional le dé la espalda al cine bélico. Me ocupé de ordenar y categorizar los primeros 25 años de la filmografía sobre Malvinas, prestando especial atención a dos películas nodales en la representación de la guerra de 1982. Los chicos de la guerra e Iluminados por el fuego marcaron los lineamientos narrativos y temáticos fundamentales que se repitieron en películas posteriores hasta el día de hoy. Por lo 
tanto, aquí me propongo pensar y analizar el estado del cine contemporáneo sobre la Guerra de Malvinas. En 2017 se cumplieron 35 ańos de la campańa militar por la recuperación de las Islas. Casualmente, ese año se estrenaron dos películas de orígenes y búsquedas estéticas muy diferentes: Soldado argentino solo conocido por Dios y Malvineitor. En este artículo buscaré dar respuestas a cómo se piensa y filma Malvinas en el presente y vislumbrar qué posibilidades le deparan a su futuro.

\section{Soldado argentino solo conocido por Dios}

Soldado argentino solo conocido por Dios se estrenó el 6 de abril de 2017 bajo la dirección de Rodrigo Fernández Engler, quien ya había transitado las aguas de la guerra con el largometraje Cartas a Malvinas (2009). Engler da forma a un film que demuestra un gran despliegue de producción y un conocimiento reconfortante en el manejo de la puesta en escena bélica. La conjunción de ciertos temas y elementos narrativos del género alivian el desasosiego de tantos años de ineficaz abordaje.

La primera escena de la película es en un barco, llamativo comienzo por ser una locación esquiva en el cine nacional en torno a esta guerra. Un pelotón de soldados esperan en silencio sentados en el suelo. Comienzan a preguntarse hacia dónde se dirigen. Un soldado cree que van hacia las Islas Sandwich a resolver un conflicto ballenero, pero otro lo alecciona afirmando que el destino es "secreto militar" y debe limitarse a cumplir órdenes. Tanto el espectador como los personajes saben que su rumbo son las Malvinas y un futuro incierto.

Un superior entra y todos callan. Juan (Mariano Bertolini) reconoce y saluda con un tímido "hola" a Ramón Molina (Sergio Surraco) quien responde desentendido. "Lo conozco de mi barrio", comenta Juan a otro conscripto y en un trillado corte la película nos lleva al pasado, a la vida civil de estos dos fraternales amigos. Juan espera a Ramón que vuelve de la colimba y en la puerta de su casa le anuncia que está saliendo con su hermana Ana (Florencia Torrente). Rispideces, acusaciones de traición y una trompada contaminan con melodrama lo que había empezado como una película de soldados rumbo a la guerra.

Juan es artista. Apasionado por el dibujo, descarga las inquietudes de su vida personal con crayones y lápices de colores mientras su madre solloza en la puerta. En sus manos tiene una carta, predeciblemente, la citación para hacer la instrucción y cumplir con su deber en las Islas Malvinas. Pero el llamado a la aventura es esquivo a nuestro "héroe" que medita la opción de escaparse a la casa de una tía en Perú y, en un acto desesperado, invita a Ana a irse con él.

Estos pequeños pasajes de novela de la tarde aplacan el envión para lo que vendrá después. Engler hace transitar a su personaje por el tortuoso entrenamiento militar, cuya referencia cinematográfica ineludible es Full Metal Jacket (1987, Stanley Kubrick): una barraca, un plano con fuga hacia el centro del cuadro y todos los soldados formados en líneas enfrentadas mientras el superior da las órdenes gritando a diestra y siniestra. Una imagen que inmortalizó Kubrick refiriendo al infierno por el 
que debe transitar un conscripto para convertirse en soldado. En Full Metal Jacket las consecuencias son tan drásticas que Vincent D’Onofrio termina pintando las paredes de un baño con sus sesos, al volarse la cabeza con una escopeta. No será el caso de la película argentina.

Soldado argentino es una de las primeras obras audiovisuales argentinas (junto con la miniserie para televisión Combatientes) que hace un poco de justicia al género bélico nacional en cuanto a la forma. La película podría pensarse como una bocanada de aire fresco al tedio y la solemnidad de casos anteriores como Iluminados por el fuego. Esta película busca acercarse, al menos demuestra intenciones, a ciertos postulados basales de la forma de filmar una batalla post Saving Private Ryan (1998, Steven Spielberg), película bisagra en la representación cinematográfica de la guerra en el siglo XXI. Engler filma con precisión las escenas de combate y desplazamientos de grupos, en especial el desembarco argentino en las Islas. Allí se observa un despliegue de producción inaudito para las películas de esta temática, con varios grupos de soldados movilizándose por la playa custodiados por tanques anfibios. La estridencia del sonido de la oruga en la arena junto al bullicio de los hombres en acción da un marco propicio para que el subteniente Quiroga (Fabio Di Tomaso) dé las directivas. Recuérdese que las películas anteriores no cuentan con misiones ni órdenes precisas sobre el desplazamiento en el territorio, hecho indispensable para el desarrollo del film bélico.

El conocimiento formal del género también se aprecia en el ataque sorpresa de un Harrier ${ }^{1}$ que dispara sobre el campamento mientras los argentinos se organizan. En un llano brumoso, que remite directamente a la fotografía gris de Fury (2014, David Ayer), un avión los toma por sorpresa volando todo por los aires. Los argentinos contestan el fuego, tanto hombres como torretas antiaéreas, en una escena de excelente factura técnica y buen ritmo. Además, el truco es invisible: el avión digital se conjuga a la perfección con los planos. Pero esta invisibilidad se ve amainada por la pasividad del héroe. Juan se queda inmóvil, estupefacto ante la metralla del Harrier que se aproxima. En un acto de arrojo, Molina lo rescata, adjudicándose el rol de héroe en la película para sí mismo y relegando a Juan al mero puesto de observador.

Esta crisis del heroísmo no es novedad para el cine nacional. Toda la representación sobre Malvinas se vio atravesada por protagonistas pasivos: desde el pesimismo de Fabián (Gustavo Belatti) en Los chicos de la guerra hasta el rostro inmutable de Esteban (Gastón Pauls) en Iluminados por el fuego. No hay lugar para los héroes en estas películas, los protagonistas son observadores del conflicto. Son la representación del ciudadano civil que se cuestiona y reflexiona sobre la guerra de 1982. No son héroes de cuerpo, son personajes intelectualizados que no miden su valor utilizando sus habilidades para salvar a los compañeros o liderando al equipo. Son conciencias, envases vacíos, carentes de liderazgo y rasgos definitorios. Juan no que-

1 Avión de combate inglés. 
da exento de esta caracterización. A lo largo de la película se cuestiona los propósitos de la contienda tal como Esteban se dirigía a los espectadores con su voz en off en Iluminados por el fuego.

Un punto a favor que contrarresta a la filmografía precedente es la búsqueda constante de mostrar el despliegue en el territorio. Como había mencionado anteriormente, una condición primordial para el género bélico es mostrar a los soldados desplazándose en el terreno, sorteando los obstáculos de topografías adversas. La ocupación o defensa de un territorio es el objetivo fundamental en una contienda bélica y este principio rige y estructura la narración. Soldado argentino demuestra, por vez primera, esa condición en el Ejército argentino. En esta película las Malvinas son un terreno transitado, donde los soldados avanzan por diferentes puntos de las islas. No es un espacio de contemplación como en los casos anteriores. Malvinas es palpable, se puede caminar.

El gran inconveniente de Soldado argentino es que no logra despegarse de una constante que afecta al cine nacional desde Los chicos de la guerra: el problema de la temporalidad. En el cine de Malvinas la temporalidad se convierte en un inconveniente, en una operación narrativa que atraviesa casi toda la filmografía sobre el conflicto. Lo que para los directores resulta una necesidad, hablar de cosas que pasaron antes y después de la guerra, para la película bélica se vuelve un obstáculo. El cine de guerra funda sus bases en la historia de soldados luchando por sobrevivir en un espacio y tiempo específicos como el campo de batalla. Barry Langford precisa esta definición de cine bélico en su texto Film Genre: Hollywood and Beyond.

Son esas escenas de combate, jugando un papel dramático central, las que definen genéricamente la película de guerra [...] La definición operativa del "combate" en la película de guerra es, desde el punto de vista del analista militar muy estrecha, y excluye muchas, si no la mayoría de las áreas clave de la guerra moderna. La película de combate, por lo general, no se centra en la planificación estratégico-militar sino en la experiencia directa de la batalla de una pequeña unidad militar con miembros y límites claramente definidos (paradigmáticamente el pelotón de infantería, la cañonera o el equipo de bombarderos) (Langford, 2003, pág. 106).

Si el cine bélico se trata de hombres buscando salir con vida de ese infierno indescriptible que es el campo de batalla, la selva ardiente de napalm o la escaramuza encarnizada en lo alto del cielo, considero que las derivaciones temporales, los saltos narrativos entre el presente de la guerra y el futuro consecuente o el pasado melancólico quitan fuerza e importancia a aquello que se quiere narrar. En el cine de Malvinas siempre importó más hablar del estado de la sociedad del momento o reflexionar sobre el conflicto a posteriori que indagar en las conductas humanas que tuvieron lugar en el combate. El punto de vista emocional de este cine se posiciona desde los civiles, el ciudadano de a pie que no encuentra explicaciones, aún hoy, para comprender cómo nuestro país le declaró la guerra a la potencia imperialista más grande de la modernidad. El cine argentino es deudor de una película que ponga 
como foco central la experiencia de la guerra. Pero no desde una mirada inquisidora sino con el fin de pensar y comprender, desde el cine, qué sintieron los soldados combatiendo en Monte Longdon o en pleno vuelo a ras del mar sobre un Pucará. ${ }^{2}$ Una película que trate de pensar desde los hechos y no desde una idea prejuzgada de lo que allí sucedió, que permita comprobar con las herramientas de la ficción e imaginar otros mundos posibles en tal contexto.

El film de Engler prometía ser un nuevo paso hacia un cine de acciones y cuerpos, regido por las normas del género. Pero, como toda la filmografía a su espalda, calló en una trampa silenciosa. Soldado argentino solo conocido por Dios no pudo escapar a la herencia opresiva de la línea testimonial. Martín Kohan, al pensar la novela fundacional Los pichiciegos de Rodolfo Fogwill, estableció dos corrientes para analizar el estado de la literatura sobre Malvinas. Su artículo El fin de una épica señala dos vertientes: una ligada a la farsa, que busca exorcizar los males de la guerra en clave picaresca, con desertores que viven bajo tierra como los "pichis" o un veterano de Malvinas hacker como en Las islas de Carlos Gamerro. Este abordaje permite evadir las variantes del relato que ponderan tanto el heroísmo triunfalista como la tragedia derrotista para narrar desde el humor y sectores limítrofes a la moralidad el devenir de sus personajes. Y, por otra parte, Kohan establece la línea testimonial como el principio rector de la mayor parte de la literatura sobre la guerra hasta el momento. Por mi parte, considero imprescindible esta categorización en tanto es el fiel reflejo de lo sucedido en nuestro cine. La corriente testimonial responde a todas aquellas obras que tienen su punto de origen en el relato directo de los combatientes donde manifiestan sus experiencias a flor de piel. Estos materiales, o si se permite el corrimiento, estos documentos, son la memoria viva de la guerra y sirvieron a lo largo de los años como forma de ordenar y comprender lo sucedido. ${ }^{3}$ Kohan puntualiza en lo siguiente:

El drama de la guerra, el drama de la gesta nacional (que resulta doblemente un drama, porque las cosas salen mal y la lucha se pierde) es narrado en otra clave y en otra clase de textos: los textos testimoniales. También de inmediato, muy cerca de los propios acontecimientos, una serie de entrevistas ofrecen la cruda versión de los soldados que pelearon en las islas y consagran una definición emblemática: "los chicos de la guerra" [...] Desde el registro del testimonio, la guerra se cuenta ineludiblemente como drama. El miedo, el frío, la soledad, las muertes, las mutilaciones, sólo admiten ser narrados con tonos sobrios. La guerra es una cosa seria (Kohan, 1999, pág. 7).

2 Avión de combate argentino.

3 Téngase en cuenta, que la información proveniente de Malvinas era censurada por el gobierno militar y prevalecían la mentira y la propaganda, como en las famosas portadas de la Revista Gente que titulaban en mayúsculas "VAMOS GANANDO". 
Desde 1984 a la fecha la fuente principal de inspiración y referencia para la producción de cine bélico fueron los materiales testimoniales. Bebe Kamín escribió Los chicos de la guerra basándose en la novela homónima de Daniel Kon y lo mismo hizo Tristán Bauer junto al excombatiente Edgardo Esteban, autor de Iluminados por el fuego. Ambas son películas de ficción con una fuerte presencia testimonial, a tal punto que en Iluminados el documental de archivo toma un lugar preponderante, como un subrayado que recuerda que lo que se ve en la ficción proviene de las entrañas de la Historia. Entonces me pregunto, ¿̨por qué no es posible que este contexto histórico permita generar una ficción más imaginativa, que rompa lazos con los testimonios, y que no dependa de la imagen de video de un veterano mirando a cámara para recordarnos lo trágico de la guerra? Un cine que dependa de sus propios artilugios narrativos para soportar el tema. Y no porque lo que se relata no sea cierto, sino porque la esencia del cine radica en otra cosa: en permitirnos, por al menos dos horas, vivir otras experiencias, ser héroes y descubrir mundos; transitar cierta elevación estética que nuestra vida rutinaria y mundana no logrará igualar.

Engler no escapa a este pantano. En una hora de película, construyó un mundo y abrió puertas que parecían cerradas para el género bélico. Pero poco a poco las fuerzas se diluyeron y la narración en Malvinas concluyó abruptamente dando paso a otra película: la testimonial. Juan es un excombatiente abandonado a su suerte en un conventillo de la ciudad, olvidado como muchos soldados que volvieron cabizbajos y escondidos por el Estado tras la derrota. Juan dibuja, y mientras pinta para purgar su penosa existencia tocan la puerta. Es Ana y carga consigo una épica íntima: la búsqueda de reconocimiento. Ella recorre oficinas, escribe cartas tratando de saber cuál fue el destino de su hermano Ramón quien se presume caído en combate, pero cuya tumba no tiene nombre. En el cementerio de Darwin, ubicado en un páramo desolado de las Islas, muchas lápidas no tienen nombre. En ellas se lee "Soldado argentino solo conocido por Dios". Guerreros sin nombre, sin identidad, sin reconocimiento.

En 2005, así como Iluminados por el fuego se ocupó de una causa desconocida para la mayoría de la sociedad como era la problemática del suicidio en los excombatientes, Soldado argentino enarbola la bandera del reconocimiento de aquellos caídos que aún no tienen una identidad. En este clima de seriedad y solemnidad se insinúa una leyenda, un disparador de la imaginación que es el "hilo de Ariadna" en la causa de Ana. Los ingleses cuentan la historia de un soldado argentino que combatió con fiereza y valentía hasta el último suspiro dándole dolores de cabeza al Ejército británico. "Lo mejor del enemigo", decían. Tras ser abatido en Tumbledown debieron darle digna sepultura y al desconocer su nombre y no tener forma de constatar su identidad lo bautizan "Pedro", un nombre común en nuestra cultura como lo puede ser Juan o Santiago. En la película Ramón es Pedro y Ana no descansará hasta poder confirmarlo.

Pero la verdad prevalecerá en las tinieblas. La burocracia militar y el desinterés de los responsables no brindarán respuesta alguna. Ana transitará los lastimosos entornos de los veteranos y familiares de caídos, olvidados tanto por la sociedad como por 
sí mismos. En Soldado argentino la épica de un civil posee más peso narrativo que la propia gesta militar. Y en esa empresa Ana empujará el alma abandonada de Juan en búsqueda de cierta luz. Al ver la vitalidad de un compañero veterano que lo arenga a salir del derrotismo que pesa sobre sus hombros y encontrando en el amor de Ana una salvación, Juan dará un paso adelante hacia una nueva vida. Previsiblemente, su renacer en la sociedad culmina en el reencuentro con su familia, cerrando así, el ciclo de los valores centrales de la Patria.

Corte a negro. Se lee la frase "En memoria de los héroes de Malvinas" mientras suena el tema musical "Aquellos otros", compuesto e interpretado por Alejandro Lerner. Este dato no es menor dado que los referentes del rock nacional siempre han tenido lugar en este cine. "Tratando de crecer" de Juan Carlos Baglieto en Los chicos de la guerra, "Botas locas" de Charly García en el cortometraje Guarisove y las sentidas estrofas de "La Memoria" en Iluminados por el fuego con la voz inconfundible de León Gieco. El rock argentino y Malvinas parecen no poder cortar sus lazos y vuelven reinventados 35 años después. El último plano del film no es para obviar. Un libro reposa sobre una tumba azotada por el viento y la lluvia Patagónica. Podemos inferir que es la Biblia o, si se quiere, el libro de la Historia que ahora descansa sobre la tumba de un veterano sin nombre dándole el reconocimiento buscado durante tantos ańos. Soldado argentino solo conocido por Dios lo intenta en la ficción, ahora será responsabilidad de la realidad culminar la epopeya.

\section{Malvineitor}

En octubre de 2017, en el marco del Festival Internacional Buenos Aires Rojo Sangre, uno de los festivales de género más peculiares e interesantes de la región, se estrenó la película Malvineitor (2017, Pablo Marini). Este film nace de las entrañas de un colectivo de cineastas que se dedica al cine de género Clase $\mathrm{B}$ hace, por lo menos, 20 años. Sin previo aviso, Pablo Marini logra romper, con un humor sumamente irreverente, convenciones y prejuicios que se interponían entre el cine bélico y la representación de la Guerra de Malvinas en el cine nacional.

Ya desde su narrativa el film llama la atención con propuestas impensadas 35 años atrás. Corre el año 2022 y, ante una crisis política y social, el presidente "vitalicio" Mauricio Macri decide invadir las Islas Malvinas en un intento desesperado por recuperar el apoyo de la población. Así, se repite la historia de 1982 pero, esta vez, en clave de guerra tecnológica donde la FAA ${ }^{4}$ tienen un as bajo la manga. Nuestras tropas cuentan con un líder, una leyenda: el soldado Malvineitor (Vic Cicuta), experimentado guerrero y entrenado para los más difíciles combates. Un Rambo argentino con toques de Commando (1985, Mark E. Lester), Predator (1987, John Mc Tiernan) y algo de Chuck Norris. Un héroe de acción como nunca se había visto en nuestra cinematografía. 
El primer punto que deslumbra de Malvineitor es su condición de parodia al género bélico, trabajando con referencias recurrentes al cine de acción y aventuras. La película de Marini abre con una batalla en la selva. Malvineitor emerge de las aguas del río tal como lo hizo el capitán Willard (Martin Sheen) en Apocalypse Now (1979), la épica de Francis Ford Coppola sobre la Guerra de Vietnam. El primer plano de nuestro héroe ya indica una referencia al cine, una lectura de los clásicos del género en clave criolla. Un helicóptero aterriza en el suelo frondoso y los argentinos son sorprendidos por soldados ingleses dando paso a un intercambio de tiros. Para sorpresa de quien escribe, de las armas surgen rayos láser como los de la saga Star Wars. Malvineitor es un gran pastiche de géneros y referencias cinematográficas que dan forma al delirio de su trama. Nuestro héroe avanza hacia el interior de las islas sorteando todo tipo de enemigos. Con su cuerpo entrenado y un sinnúmero de habilidades para sobrevivir a la intemperie se abre paso por la selva en solitario. Pero pesa sobre él una maldición: tiene una reiterada mala suerte para elegir a sus compañeros, quienes siempre caen muertos en combate.

Bajo la estética del "cine de bajo presupuesto" Marini hace uso de toda una serie de artilugios para exacerbar las características de su película gore y de grandes logros técnicos. La imagen posee mucho grano y los pelos característicos de las malas copias fílmicas del cine explotation de los ańos setenta, junto con saltos de montaje producto de la película velada. A la desprolija textura visual se le suma un logrado trabajo sonoro con un exagerado doblaje que extrema la falsedad del film desfasando el audio de los diálogos. Marini tiene las mismas búsquedas estéticas que Robert Rodriguez en Planet Terror (2007) pero con miles de dólares de desventaja. Así mismo, la osadía del director llega al punto de robar planos de documentales de animales como los de National Geographic o la BBC, mostrando jaguares, monos y pájaros tropicales para darle el marco natural más equivocado y delirante posible al contexto de Malvinas.

Malvineitor responde con creces a los postulados del cine bélico y del género de acción. Es un personaje arquetípico con habilidades especiales, una leyenda entre sus camaradas, pero un héroe solitario que sólo piensa en el cumplimiento de su deber. La película responde a la estructura narrativa prevista por el género, el héroe avanza en la particular misión de destruir el arma secreta de los ingleses: un monstruo alienígena de grotescas connotaciones sexuales encerrado en un container, como el velociraptor de la primera Jurassic Park (1993, Steven Spielberg). Malvineitor también actúa conforme a los tropos propios de la narración clásica y derivaciones del cine de aventuras. En esta guerra emprende un viaje de autoconocimiento para descubrir sus orígenes. Recibe el llamado a la aventura en un ritual de iniciación aborigen bebiendo un brebaje recetado por un chamán quien le encomienda encontrar la "Puerta de hierro" en su camino por conocer a sus verdaderos progenitores.

La línea de la farsa, propuesta por Kohan en El fin de una épica, encuentra su primer exponente cinematográfico con Malvineitor. En 1995 el cortometraje Guarisove, los olvidados de Bruno Stagnaro había dado un primer paso hacia una narrativa 
más cercana a la picaresca de Los pichiciegos. Esta pequeña comedia significó toda una novedad en 35 ańos de cine argentino al ser el único caso que representó la Guerra de Malvinas en clave de humor. Retomando formas y estilos de películas como M.A.S.H. (1972, Robert Altman) y Catch 22 (1970, Mike Nichols), Stagnaro se animó a pensar los delirios de la guerra contando la historia del último grupo de argentinos en las Islas. Guarisove no tuvo herencia en el cine argentino hasta la aparición de Malvineitor que da un paso más allá para mirar la guerra desde la parodia.

La parodia en el cine bélico comprende un intermitente abordaje en la Historia del cine. Los ańos ochenta en Hollywood fueron la panacea de la parodia de los géneros populares. El cine catástrofe tuvo la propia con Airplane! (1980, Jim Abrahams, David Zucker, Jerry Zucker), el policial en The Naked Gun: From the Files of Police Squad! (1988, David Zucker), el cine de espías y las películas de Elvis Presley con Top Secret! (1984, Jim Abrahams, David Zucker, Jerry Zucker) y las sagas intergalácticas en Spaceballs (1987, Mel Brooks). En los noventa, bajo la mirada de Abrahams, le tocó el turno al cine bélico con la desopilante Hot Shots! (1991) y su segunda parte Hot Shots Part Deux (1993). Esta última se ocuparía de recorrer grandes hitos del cine de guerra pasando por Apocalypse Now, The Deer Hunter (1978, Michael Cimino) y Rambo (First Blood, 1982, Ted Kotcheff). Pero la parodia fundamental del género, que deberá ser recordada en la posteridad, es la obra maestra del actor y director Ben Stiller, Tropic Thunder (2008). La inteligencia de esta película no solo radica en revisitar y caricaturizar el cine norteamericano sobre la guerra de Vietnam sino también en su trabajo metalingüístico respecto a las dificultades de un rodaje de estas características. Tropic Thunder son dos películas dentro de una: la producción accidentada de un largometraje bélico con estrellas egocéntricas (guiño a lo ocurrido en la filmación de Apocalypse Now) y la película bélica que los actores creen estar filmando. Stiller demuestra que puede ser un director de carácter filmando una comedia a la manera que los veteranos directores del pasado filmaron el género, manejando con ingenio un doble dispositivo narrativo que genera tanto risas como asombro.

Malvineitor, opera con la parodia a su modo, por momentos montada sobre la narración del cine bélico, jugando con Vietnam y el cine de acción de los 80, para luego trasladarse a otros géneros como el cine de aventuras y la ciencia ficción. Mientras el comic relief argentino ironiza con la caracterización de Guillermo Francella en Exterminators (1989, Carlos Galettini), los enemigos ingleses responden a formas propias del cine de acción, vestidos de negro, musculosos y eximios en artes marciales. Resulta muy interesante el villano Terry Butcher (Andres Borghi) un escuálido soldado de capa que intimida con su voz socarrona y demacrado semblante. Bucher

5 La inclusión de un personaje humorístico, una escena o un diálogo ingenioso en un trabajo serio. Cumple el fin de aliviar la tensión dramática. 
responde al mando de Margaret Thatcher, que se comunica desde Londres mediante un holograma, dispositivo inmortalizado en la ciencia ficción por Star Wars.

Una peculiaridad de la película es su planteo temporal. Es la primera película argentina que acota la totalidad de su relato al combate en las Islas, sin derivar entre el pasado o la posguerra como las películas nacionales antes mencionadas. Pero es aún más importante destacar que Malvineitor ubica su narración en el futuro, no narra la guerra de 1982 sino que propone una reinterpretación de la misma en el siglo XXI. Este espejismo temporal permite desligarse de las ataduras de la corriente testimonial ampliando los límites de la ficción a situaciones que no habíamos visto hasta el momento. Tal es la conciencia del corrimiento testimonial que Marini hasta se permite hacer un guiño a Iluminados por el fuego utilizando un plano de Gastón Pauls y su mirada pasiva, esa que lo caracteriza a lo largo de todo el film. Esta pequeńa operación vaticina el agotamiento de la corriente testimonial y es un llamado la búsqueda de otras estéticas más atractivas para el tratamiento de Malvinas en el cine.

Malvineitor finaliza con una espectacular batalla final. El monstruo inglés crece en proporciones gigantescas, convirtiéndose en una amenaza para todos los que se encuentran en la isla. En la búsqueda por conocer su pasado, Malvineitor es guiado por el anciano Oesterheld ${ }^{6}$ (Germán Baudino) en las catacumbas de la isla. Allí el héroe se hace con el arma que pondrá fin al conflicto tanto bélico como personal. Reconocerá que es hijo de desaparecidos y se abren las puertas a un robot gigante con forma de dinosaurio. En un piano suenan las notas del tema "Los dinosaurios" de Charly García que se convierte en la banda de sonido anticipando un duelo titánico. Con la fuerte impronta del programa de televisión Power Rangers de los años 90 inicia una pelea desopilante entre el monstruo y el robot. La película se vuelve un pastiche de referencias a las películas Kaiju, al cine de artes marciales y a la ciencia ficción. Los efectos especiales juguetean con los límites de lo falso y lo espectacular. Por primera vez en el cine nacional, los argentinos ganan la guerra y considero que Malvineitor no solo gana la batalla en el plano narrativo sino que abre una ventana en el cine nacional. Marini, no entra por la puerta del cine bélico, no pide permiso. Salta por la ventana, rompiendo prejuicios cristalizados, riéndose de lo que "no se debe". Demuestra que, una vez más, desde el cine independiente surgen las renovaciones culturales. Tal como lo hicieron los "Movie Brats" en los setenta en el cine norteamericano, una nueva generación de directores puede hacerse cargo de los temas solemnes y darles una vuelta de tuerca respondiendo con la potencia del cine.

\section{8, hoy}

El 2018 propuso un resurgir del tema Malvinas en el ámbito intelectual y cultural. El estreno de Teatro de guerra (2018, Lola Arias) puso nuevamente sobre la mesa

6 Héctor Germán Oesterherld guionista de El Eternauta (1957-1959), historieta de ciencia ficción argentina. Desaparecido en 1977 por la Dictadura militar. 
el problema de los excombatientes, agregando un elemento novedoso al trabajo de la representación: la búsqueda de hermanar lazos con los veteranos ingleses. Este documental, basado en la multipremiada obra de teatro Campo minado, realizada por el mismo elenco y directora, busca indagar en las experiencias y memorias de tres combatientes argentinos y tres ingleses 35 años después de la guerra. Un juego teatral con los verdaderos protagonistas de la historia, un espacio de comunión y aprendizaje para los integrantes de cada "bando".

El trabajo de Lola Arias sobre Malvinas comienza años atrás. El proyecto nació en 2013 a raíz de una videoinstalación titulada Veteranos, realizada en el LIFT (Festival Internacional de Teatro de Londres). Allí excombatientes argentinos reconstruían sus recuerdos de Malvinas desde los lugares en los que trabajan y viven hoy. Este fue el disparador de la obra de teatro Campo minado, para la que Arias tuvo la misión de mediar entre veteranos de ambas nacionalidades con el fin de crear un proyecto artístico que limase las asperezas de la Historia. Tanto la película como la obra indagan en los mecanismos de la memoria, en cómo el ser humano revive experiencias traumáticas del pasado.

Teatro de guerra, no es documental ni ficción. Es un híbrido que se nutre de ambos dispositivos para sacar el mejor resultado de la vivencia que se está produciendo en la realidad. Antiguos enemigos recorren una casa abandonada, una pileta, un cuartel. Cada uno viene con bagajes culturales diversos y hasta antagónicos. Lou Armour fue fotografiado en la rendición del 2 de abril y su cara se vio por el mundo entero en la tapa de los diarios, Ruben Otero, sobreviviente al hundimiento del ARA General Belgrano, hoy tiene una banda tributo a los Beatles. David Jackson transcribía mensajes de radio y desempeña su rol de psicólogo asistiendo a veteranos de guerra. Gabriel Sagastume, abogado penalista, se negó a disparar durante todo el combate, mientras que Marcelo Vallejo fue apuntador de mortero y eximio corredor de triatlón. Inclusive los Gurkhas ${ }^{7}$ tienen un lugar en esta historia, Sukrim Rai demuestra sus habilidades con el cuchillo (kukri) relatando su presente como guardia de seguridad.

Lo teatral, el testimonio y el cine se conjugan de manera única e irrepetible para explorar el sinsentido de la guerra a partir de quienes estuvieron allí. Se presentan, muestran sus recuerdos, sus prendas de aquella época. Un experimento artístico con ligazones al célebre documental Shoah (1985, Claude Lanzmann) y a The Act of Killing (2012, Joshua Oppenheimer). Parte teatro, parte video instalación, el documental recorre diferentes escenarios recreando momentos y proponiendo intercambios. La música es el idioma universal que permite comunicar a estos hombres que no comparten la lengua del otro. Tocan juntos con la vitalidad de una banda de adolescentes en el garaje de una casa demostrándole al mundo que los lazos de la humanidad no pueden ser destruidos ni por los gobiernos ni por las bombas. 
Concluyendo este análisis, me detengo a reflexionar si es el cine la única respuesta posible a abordar la Guerra de Malvinas desde una perspectiva bélica. Quizás, en un intento forzoso por adjudicarle al cine la potestad de narrar la guerra con la estridencia del sonido y la magnanimidad de la imagen, otras obras artísticas están esperando obtener mayor visibilidad. La obra de teatro Campo minado, reestrenada en Buenos Aires a propósito del documental Teatro de guerra, propone una potencia emocional y narrativa que no se percibe en 35 años de cine argentino. Aún desde las fibras más profundas de la corriente testimonial, la obra se permite hacer ficción de un vuelo creativo notable. Un momento que pone la piel de gallina es el relato de Otero sobre el hundimiento del Belgrano. El excombatiente toca la batería mientras un veterano inglés muestra fotografías del marino tomadas sobre el buque días atrás, proyectadas en una pantalla grande. Otero enumera datos (cifras, longitudes de las islas, cantidad de combatientes, etc.) y, a medida que los números muestran la cara más penosa de la guerra, su solo de batería se vuelve violento, ecléctico y mordaz. Las luces se apagan y una luz estroboscópica, impone un clima de incomodidad y desconcierto guiado por los golpes exorcizantes de Otero en los platillos. Una montańa rusa de emociones, imágenes y sonidos que el cine todavía no ha podido retratar.

El arte gráfico también merece una mención en este escenario. Si bien mi capacidad de análisis puede verse limitada o inexacta no puedo obviar la dicha que me generó descubrir la novela gráfica Malvinas, el cielo es de los halcones. Con guión de Néstor Barron e ilustrado por Walther Taborda, esta historieta editada en 2016 ocupa el espacio vacío en la representación de las proezas de la Fuerza Aérea Argentina en Malvinas. Esta verdadera obra de arte se encuentra dividida en tres tomos a todo color: Skyhawk, Pucará y Super-Étendard. Cada libro relata la historia de los tres modelos de aeronave utilizadas por los argentinos y reconocidas en el mundo entero por las proezas militares y estratégicas que llevaron a cabo en 1982.

Si el cine posee limitaciones artísticas, al estar atado a altos costos y presupuestos que nuestra industria no está en condiciones de soportar, no es casualidad que un arte "más barato" como la ilustración sea el medio ideal para relatar este tipo de historias. Cada página de Malvinas, el cielo es de los halcones parece el storyboard de una película de Hollywood. Taborda imagina complejas batallas aéreas poniendo el punto de vista en lugares originales que deslumbran de espectacularidad. Las imágenes coloridas se ajustan a las necesidades del género bélico. Cada cuadro trabaja conforme a la lógica de montaje del cine infundiendo a la lectura un ritmo sin igual.

Barron y Taborda hacen justicia al olvido de las proezas aéreas en la representación artística nacional dando visibilidad a la importancia de la aviación en el desarrollo del combate. Valores como la valentía, la entrega y el honor desbordan las páginas del comic demostrando un alto grado de conocimiento en materia militar y un refinado gusto artístico. Tomo tras tomo se leen con adrenalina complejas secuencias que uno sueña con ver en la pantalla grande. 
Quizás el cine necesite un recambio tanto artístico como generacional. Directores más jóvenes, sin ataduras ideológicas al conflicto que puedan ver con otra perspectiva las posibilidades narrativas y visuales que la Guerra de Malvinas tiene para ofrecer. Artistas de otras disciplinas ya se encuentran rompiendo los prejuicios de la Historia produciendo obras que enaltecen las hazañas logradas por los soldados en las islas. El género bélico ha ido encontrando su lugar desde las trincheras del arte independiente y demostró su potencia visual en la novela gráfica. El teatro se permitió jugar con éxito entre la ficción y el testimonio movilizando con recuerdos y emociones tanto a quienes están sobre las tablas como a los espectadores en sus butacas. Es tiempo de que el cine industrial se ocupe de estas historias y, aprendiendo de las grandes epopeyas del cine norteamericano, busquemos filmar nuestras islas rindiendo honor a todos aquellos que dejaron su vida por recuperarlas.

\section{Referencias}

Altares, Guillermo (1999). Esto es un infierno: Los personajes del cine bélico. Madrid: Alianza Editorial.

Fernández, Ezequiel (2018). Esto es la guerra, pibe: El cine bélico en la representación de la Guerra de Malvinas. Buenos Aires: Universidad del Cine/Elaleph.com.

Kohan, Martín (1999). "El fin de una épica". Buenos Aires. Punto de Vista No 64.

Langford, Barry (2003). Film Genre: Hollywood and Beyond. Edinburgo: Edinburgh University Press Ltd.

\section{Filmografía}

Airplane! (1980, EE.UU., Jim Abrahams, David Zucker, Jerry Zucker)

Apocalypse Now (1979, EE.UU., Francis Ford Coppola)

Cartas a Malvinas (2009, Argentina, Rodrigo Fernández Engler)

Catch 22 (1970, EE.UU., Mike Nichols)

Combatientes (2013, Argentina, Jerónimo Paz Clemente y Tomás de las Heras)

Commando (1985, EE.UU., Mark E. Lester)

Exterminators (1989, Argentina, Carlos Galettini)

First Blood (1982, EE.UU.,Ted Kotcheff)

Full Metal Jacket (1987, EE.UU., Stanley Kubrick)

Fury (2014, EE.UU., David Ayer)

Guarisove, los olvidados (1995, Argentina, Bruno Stagnaro)

Hot Shots Part Deux (1993, EE.UU., Jim Abrahams)

Hot Shots! (1991, EE.UU., Jim Abrahams)

Iluminados por el fuego (2005, Argentina, Tristán Bauer)

Jurassic Park (1993, EE.UU., Steven Spielberg)

Los chicos de la guerra (1984, Argentina, Bebe Kamín) 
M.A.S.H. (1972, EE.UU., Robert Altman)

Malvineitor (2017, Argentina, Pablo Marini)

Planet Terror (2007, EE.UU., Robert Rodríguez)

Predator (1987, EE.UU., John Mc Tiernan)

Saving Private Ryan (1998, EE.UU., Steven Spielberg)

Shoah (1985, Francia, Claude Lanzmann)

Soldado argentino solo conocido por Dios (2017, Argentina, Rodrigo Fernández Engler)

Spaceballs (1987, EE.UU., Mel Brooks)

Teatro de guerra (2018, Argentina, Lola Arias)

The Act of Killing (2012, Dinamarca; Reino Unido; Noruega, Joshua Oppenheimer) The Deer Hunter (1978, EE.UU., Michael Cimino)

The Naked Gun: From the Files of Police Squad! (1988, EE.UU., David Zucker)

Top Secret! (1984, EE.UU., Jim Abrahams, David Zucker, Jerry Zucker)

Tropic Thunder (2008, EE.UU., Ben Stiller) 
